\title{
Structural MRI in Autism Spectrum Disorder
}

\author{
RONG CHEN, YUN JIAO, AND EDWARD H. HERSKOVITS \\ Department of Radiology, University of Pennsylvania, Philadelphia, Pennsylvania 19104
}

\begin{abstract}
Magnetic resonance (MR) examination provides a powerful tool for investigating brain structural changes in children with autism spectrum disorder (ASD). We review recent advances in the understanding of structural MR correlates of ASD. We summarize findings from studies based on voxel-based morphometry, surface-based morphometry, tensor-based morphometry, and diffusiontensor imaging. Finally, we discuss diagnostic models of ASD based on MR-derived features. (Pediatr Res 69: 63R-68R, 2011)
\end{abstract}

A utism spectrum disorder (ASD) $(1,2)$ is a heterogeneous disorder (or collection of related disorders) of multifactorial etiology, with great range in severity of symptoms. ASD affects $\sim 1$ in 166 children and is four times more prevalent in boys than in girls. Core features of individuals with autism include the following: 1) impairment in reciprocal social interactions; 2) verbal and nonverbal communication deficits; 3) repetitive and ritualized behaviors; and 4) a narrow range of interests. Approximately $30 \%$ of individuals with ASD manifest some degree of mental retardation (3).

Magnetic resonance (MR) examination allows researchers and clinicians to noninvasively examine brain anatomy in vivo. Structural MR examination is widely used to investigate brain morphology because of its high-contrast sensitivity and spatial resolution and because it entails no radiation exposure; the last feature is particularly important for children and adolescents (4). MR diffusion-tensor imaging (DTI) assesses the direction of water diffusion for each voxel; this technique is sensitive to loss of white-matter (WM) integrity and to differences in connectivity.

Structural MR examination provides several means by which researchers can delineate structural changes in the brains of individuals with ASD. We will review recent advances in our understanding of the structural MR correlates of ASD. We will review analytic methods that researchers have applied to structural MR data, such as voxel-based morphometry (VBM), surface-based morphometry (SBM), and tensorbased morphometry (TBM), longitudinal MRI studies, and DTI studies of ASD. Finally, we will review efforts to generate predictive models of ASD based on MR-derived features.

Received October 25, 2010; accepted January 6, 2011

Correspondence: Rong Chen, Ph.D., 3600 Market Street, Science Center, Philadelphia, PA 19104; e-mail: rong.chen@uphs.upenn.edu

R.C. and E.H.H. are supported by National Institutes of Health Grant R01 AG13743, which is funded by the National Institute of Aging, the National Institute of Mental Health, and the National Cancer Institute. They are also supported by NIH R03 EB009310. R.C. is supported by Institute for the Translational Medicine and Therapeutics fellowship of University of Pennsylvania. Y.J. is supported by the China Scholarship Council (Project number 2008101370), the National Natural Science foundation of China (Project number 30570655), and the Scientific Research Foundation of Graduate School of Southeast University (YBJJ1011)

\section{Structural MR in ASD}

There exists an extensive literature centered on the use of structural MRI to identify abnormalities in patients with ASD. Based on the image-analysis methods applied to the structural (i.e. image) data, these studies can be classified into region-ofinterest (ROI)-based, VBM-based, SBM-based, or TBM-based.

ROI-based analysis requires experts to manually or semimanually delineate brain regions. Depending on the degree of automation, this process may be labor intensive and time consuming. An inherent bias in ROI-based analysis is that such studies can analyze only a limited number of brain regions, and the results clearly depend on the ROIs chosen by investigators. However, to the extent that the voxels within a region manifest similar structural abnormalities common to patients with ASD, the use of ROIs will increase statistical power. In contrast, voxel-wise approaches assess structural changes throughout the brain and may be more appropriate when no consensus exists regarding brain regions thought to be central to ASD. VBM, SBM, and TBM are examples of voxel-wise morphometric analysis methods.

ROI-based volumetry. MR studies of total brain volume demonstrate that young children with ASD (age, 18 mo-4 y) have 5-10\% abnormal enlargement in brain volumes compared with those of normal controls (5-7). This finding seems to be related to increases in both gray-matter (GM) and WM volumes, but not to ventricular volumes (7). However, whether this abnormal enlargement persists or not into later childhood and adolescence is not as clear $(5,8)$.

Researchers have focused particular attention on the corpus callosum: reduced volumes in the anterior (genu and rostrum), middle (body), and posterior (isthmus and splenium) callosal subregions have been reported in juveniles and adults with ASD (9-12). For example, Piven et al. (12) used T1-weighted MRI to examine the size of the anterior, body, and posterior subregions of the corpus callosum in autistic individuals $\{26$ males and 9 females, mean age $=18 \mathrm{y}$ [SD 4.5] and normal controls [20 male and 16 female, mean age $=20.2$ y (SD 3.8)]\}. They found a significantly smaller average size of the body and posterior subregions of the corpus callosum in the autistic individuals.

\footnotetext{
Abbreviations: ADC, apparent diffusion coefficient; ASD, autism spectrum disorder; DTI, diffusion-tensor imaging; FA, fractional anisotropy; GM, gray-matter; MR, magnetic resonance; ROI, region-of-interest; SBM, surface-based morphometry; TBM, tensor-based morphometry; VBM, voxelbased morphometry; WM, white-matter
} 
Increased amygdala volumes have been reported in children with ASD (6,13). In a meta-analysis (14), Stanfield et al. reported that enlargement of amygdala present in children with ASD was not found in older subjects. They found significant relationships between age and effect size for the left and right amygdala. As age increases amygdala volume in autistic subjects decreases relative to controls.

Voxel-based morphometry. In VBM studies, there are two principal features: tissue density and tissue volume (15). For density-based analysis, researchers have focused on the relative concentrations of GM and WM structures in spatially normalized images (i.e. the proportions of GM and WM to all tissue types within a region). However, many studies instead aim to detect regional differences in volumes of a particular tissue (GM or WM). These studies are volume-based.

Table 1 summarizes VBM studies of ASD. Ideally, we would aggregate the results of these VBM studies at the voxel level; however, there are two major barriers to this approach. First, we cannot compare the coordinates of voxels across studies that use different brain templates. Second, different studies use different image-processing pipelines. There is significant variability in choices of registration methods and smoothing-kernel parameters, among other aspects of image processing. Therefore, even for studies using the same brain template, the chance that voxel coordinates would remain consistent across studies is low.

Given this difficulty with aggregating results at the voxel level, we have summarized VBM findings at the lobar level. When we pooled density-based and volume-based studies together, we found that there was no consistent pattern of regional specificity with respect to GM and WM differences. However, interesting patterns emerged when we analyzed density-based and volume-based studies separately. For volume-based studies, the mean age for the ASD group ranged from 8.9 to $31 \mathrm{y}$. For density-based studies, the mean age for the ASD group ranged from 9.3 to $32 \mathrm{y}$. We compared the mean ages for the ASD group between volume-based studies and density-based studies using the two-sample $t$ test and found no significant difference $(p=0.807)$.

For each combination of study type (volume-based or density based) and anatomic structure (frontal, temporal, parietal, and occipital lobes and the limbic system), we identified the most frequently occurring pattern, which we call prototypical. For example, we identified seven studies investigating GM density changes in the frontal lobe; among them, four reported decreased GM density, two reported no change, and one reported increased GM density; thus, the prototypical pattern was decreased GM density.

For volume-based studies, there is evidence for increased GM volumes in the frontal, temporal, and parietal lobes and in the limbic system, and decreased WM volumes in the frontal and temporal lobes and in the limbic system. Similarly, there is evidence for decreased GM density in the frontal and temporal lobes, and decreased WM density in the temporal lobe.

Both density-based and volume-based studies reported GM differences in the frontal and temporal regions. The most striking difference between volume-based and density-based studies is the direction of the abnormality. The majority of volume-based studies reported increased GM volume in these regions, whereas most density-based studies reported decreased GM density. For WM, both volume and density tend to decrease in the temporal lobe.

Surface-based morphometry. The intrinsic topology of the cerebral cortex is that of a 2-D sheet with a highly folded and curved geometry; VBM cannot directly measure this topology. In contrast, SBM centers on cortical topographic measurements, and thereby provides information complementary to that provided by VBM.

Table 2 summarizes several studies of cortical thickness changes in patients with ASD (16-19). Among them, two $(16,19)$ studies are voxel-based, and two $(17,18)$ are atlasbased. The mean age for the ASD group ranges from 9.2 to $33 \mathrm{y}$. The changes occur primarily in the frontal, temporal, and parietal lobes but not in the occipital lobes. However, the direction of change (cortical thinning versus increased cortical thickness) is not consistent across studies for the frontal and temporal lobes. The majority of studies reported increased cortical thickness in the parietal lobes (17-19).

Hardan et al. (20) investigated gyrification patterns in autism. They found in the autistic group, left frontal gyrification index was higher in children and adolescents but not in adults. Cortical folding was decreased bilaterally with age in the total ASD sample but not in controls.

Tensor-based morphometry. Both TBM and VBM measure volume changes. The advantage of TBM over VBM is that false-positive findings due to systematic group differences in registration errors are less likely. This is because in TBM, the signals analyzed are generated based on the registration of the images rather than on aligned segmented GM. That is, TBM does not require GM be perfectly registered across subjects. Brun et al. (21) used TBM to analyze T1-weighted MR images of 24 male children with ASD [mean age, 9.5 y (SD 3.2)] and 26 age-matched controls. They found significantly decreased GM volumes in the parietal, left temporal, and left occipital lobes, bilaterally.

Longitudinal MRI studies. The studies in previous sections are cross-sectional; that is, they aim to detect differences in structural MRI features between individuals with ASD and age-matched controls. When researchers are interested in the effects of age on ASD, i.e. the trajectory of brain growth in ASD, they perform longitudinal studies (22).

Schumann et al. (23) performed a longitudinal study of brain growth in young children with ASD. For each child, a structural MRI scan was acquired at multiple time points beginning at $1.5 \mathrm{y}$ up to $5 \mathrm{y}$ of age. They collected $193 \mathrm{MRI}$ scans on 41 toddlers who received a confirmed diagnosis of autistic disorder at about 48 mo of age and 44 typically developing controls. Volumes of eight ROIs (frontal GM, temporal GM, parietal GM, occipital GM, cingulate GM, total $\mathrm{GM}$, total WM, and total cerebral volume) were calculated using FreeSurfer. They found that all regions except occipital GM undergo an abnormal growth trajectory. The cerebrum and several of its subdivisions in most children with ASD was enlarged by $2.5 \mathrm{y}$ of age. 
Table 1. VBM studies of ASD

\begin{tabular}{|c|c|c|c|c|}
\hline ASD & Comparison & Methods & Findings (ASD relative to controls) & Reference \\
\hline $\begin{array}{l}\text { DSM-IV; } 15 \text { individuals with } \\
\text { HFA (12 male); mean age } \\
28 \text { y (SD 6.6) }\end{array}$ & $\begin{array}{l}15 \text { age- and sex-comparable } \\
\text { normal controls }\end{array}$ & $\begin{array}{l}\text { 2T } 1.5-\mathrm{mm} \text { thick; SPM96; GM and } \\
\text { WM density; total amount of } \\
\text { GM as covariates in ANCOVA }\end{array}$ & $\begin{array}{l}\uparrow \text { GM density in posterior parts of amygdala, } \\
\text { and cerebellum; } \downarrow \text { GM density in anterior } \\
\text { part of amygdala }\end{array}$ & $(38)$ \\
\hline $\begin{array}{l}\text { ICD 10, ADI-R; } 21 \text { adults } \\
\text { with Asperger's syndrome } \\
\text { (19 male); mean age } 32 \mathrm{y} \\
\text { (SD 10) }\end{array}$ & $\begin{array}{l}24 \text { healthy controls ( } 22 \\
\text { male); mean age } 33 \\
\text { (SD 7) }\end{array}$ & $\begin{array}{l}1.5 \mathrm{~T} 1.5-\mathrm{mm} \text { thick; GM and WM } \\
\text { density; age and IQ as } \\
\text { ANCOVA covariates }\end{array}$ & $\begin{array}{l}\downarrow \text { GM density in frontostriatal and cerebellar } \\
\text { regions; widespread differences in WM }\end{array}$ & (39) \\
\hline $\begin{array}{l}\text { DSM-IV, ADI-R; } 21 \text { children } \\
\text { with autistic disorder (16 } \\
\text { male); mean age } 9.3 \mathrm{y} \\
\text { (SD 2.2) }\end{array}$ & $\begin{array}{l}12 \text { healthy children (7 male); } \\
\text { mean age } 10.8 \text { (SD 2.7) }\end{array}$ & $\begin{array}{l}\text { 1.5T } 1.2-\mathrm{mm} \text { thick; SPM99; GM } \\
\text { and WM density; global mean } \\
\text { voxel value as a covariate in } \\
\text { ANCOVA }\end{array}$ & $\begin{array}{l}\downarrow \text { GM density in superior temporal sulcus; } \\
\downarrow \text { WM density in right temporal pole and } \\
\text { in cerebellum }\end{array}$ & $(40)$ \\
\hline $\begin{array}{l}\text { DSM-IV, ADI-R, and } \\
\text { ADOS; } 9 \text { males with } \\
\text { HFA, mean age } 14 \text { y (SD } \\
\text { 3.3), and } 11 \text { with ASP, } \\
\text { mean age } 13.5 \text { y (SD 2.4) }\end{array}$ & $\begin{array}{l}13 \text { male controls; mean age } \\
13.6 \text { y (SD 3.1) }\end{array}$ & $\begin{array}{l}\text { 3T } 1.5-\mathrm{mm} \sim 1.6-\mathrm{mm} \text { thick; } \\
\text { SPM99; GM density }\end{array}$ & $\begin{array}{l}\text { HFA and ASP have } \downarrow \text { GM density in right } \\
\text { inferior temporal gyrus, entorhinal cortex, } \\
\text { right rostral tip of fusiform gyrus }\end{array}$ & $(41)$ \\
\hline $\begin{array}{l}\text { DSM-IV, ADI-R, ADOS-G; } \\
16 \text { male individuals with } \\
\text { Autistic disorder or } \\
\text { Asperger's syndrome; } \\
\text { mean age } 15.4 \text { y (SD 2.2) }\end{array}$ & $\begin{array}{l}16 \text { age-, sex- and } \\
\text { IQ-matched controls }\end{array}$ & $\begin{array}{l}\text { 1.5T } 1.6-\mathrm{mm} \text { thick; SPM2; GM } \\
\text { and WM volumes; total brain } \\
\text { volume as ANCOVA covariate }\end{array}$ & $\begin{array}{l}\uparrow \mathrm{GM} \text { volume in right fusiform gyrus, right } \\
\text { temporo-occipital region and the left frontal } \\
\text { pole; } \downarrow \text { GM volume in right thalamus }\end{array}$ & $(42)$ \\
\hline $\begin{array}{l}\text { DSM-IV, ADI-R, ADOS-G; } \\
15 \text { male individuals with } \\
\text { ASD (IQ > 70); mean age } \\
15.2 \text { y (SD 2.2) }\end{array}$ & $\begin{array}{l}16 \text { age-, sex- and } \\
\text { IQ-matched controls }\end{array}$ & $\begin{array}{l}\text { 1.5T } 1.6-\mathrm{mm} \text { thick; SPM2; GM } \\
\text { and WM volume; total brain } \\
\text { volume as ANCOVA covariate }\end{array}$ & $\begin{array}{l}\downarrow \text { WM volume in corpus callosum, left } \\
\text { middle temporal, right middle frontal, and } \\
\text { left superior frontal gyri }\end{array}$ & $(43)$ \\
\hline $\begin{array}{l}\text { ICD } 10, \text { ADI-R; } 17 \text { with } \\
\text { Autism (16 male); mean } \\
\text { age } 12 \text { y (SD } 1.8)\end{array}$ & $\begin{array}{l}17 \text { typically developing } \\
\text { control (16 male); mean } \\
\text { age } 12 \text { (SD 1.8) }\end{array}$ & $\begin{array}{l}\text { 1.5T 3-mm thick; BAMM; GM } \\
\text { and WM density }\end{array}$ & $\begin{array}{l}\downarrow \text { GM density in frontostriatal and parietal } \\
\text { networks, in ventral and superior temporal } \\
\text { gyrus; } \downarrow \text { WM density in the cerebellum, } \\
\text { left internal capsule and fornices }\end{array}$ & $(44)$ \\
\hline $\begin{array}{l}\text { DSM-IV, ADI, ADOS; } 24 \\
\text { male individuals with } \\
\text { autism; mean age } 21 \mathrm{y} \\
\text { (SD 11) }\end{array}$ & $\begin{array}{l}23 \text { male controls; mean age } \\
21 \text { (SD 11) }\end{array}$ & $\begin{array}{l}1.5 \mathrm{~T} 1.7-\mathrm{mm} \text { thick; SPM2; GM } \\
\text { and WM volume; total GM } \\
\text { volume and age as ANCOVA } \\
\text { covariates }\end{array}$ & $\begin{array}{l}\uparrow \text { GM volume in the medial frontal gyri, left } \\
\text { pre-central gyrus, right postcentral gyrus, } \\
\text { right fusiform gyrus, caudate nuclei and left } \\
\text { hippocampus. } \downarrow \text { GM volume in the } \\
\text { cerebellum }\end{array}$ & $(45)$ \\
\hline $\begin{array}{l}\text { DSM-IV, ADI-R; } 33 \text { children } \\
\text { with either Asperger's } \\
\text { syndrome or HFA ( } 27 \\
\text { male); mean age } 11 \text { y } \\
\text { (SD 2) }\end{array}$ & $\begin{array}{l}55 \text { typical developing control } \\
\text { children balanced for age, } \\
\text { IQ, gender, maternal } \\
\text { language and ethnicity }\end{array}$ & $\begin{array}{l}\text { 1.5T 3-mm thick; BAMM; GM } \\
\text { and WM density }\end{array}$ & $\begin{array}{l}\downarrow \text { GM density in left dorsolateral prefrontal } \\
\text { cortex, bilateral basal ganglia, inferior } \\
\text { cerebellar vermis, left superior temporal } \\
\text { cortex and bilateral posterior parietal cortices }\end{array}$ & $(46)$ \\
\hline $\begin{array}{l}\text { DSM-IV and ICD-10; } 12 \\
\text { male with classic autism; } \\
\text { mean age } 12.4 \text { y (SD 4) }\end{array}$ & $\begin{array}{l}16 \text { male controls; mean age } \\
\text { of } 13.2 \pm 5 \mathrm{y}\end{array}$ & $\begin{array}{l}\text { 2T 1-mm thick; SPM5; GM and } \\
\text { WM volume }\end{array}$ & $\begin{array}{l}\uparrow \mathrm{GM} \text { volume in medial and dorsolateral } \\
\text { frontal areas, in the lateral and medial parts of } \\
\text { the temporal lobes, in the parietal lobes, } \\
\text { cerebellum and claustrum; } \downarrow \text { WM volume in } \\
\text { frontal, parietal, temporal and occipital lobes }\end{array}$ & $(47)$ \\
\hline $\begin{array}{l}\text { DSM-IV, ADI-R, CARS; } 17 \\
\text { children with } \\
\text { high-functioning autism } \\
\text { (14 male); mean age } 8.88 \\
\text { y (SD 1.96) }\end{array}$ & $\begin{array}{l}15 \text { gender-, age-, and IQ- } \\
\text { matched controls (12 } \\
\text { male); mean age } 9.73(\mathrm{SD} \\
1.67)\end{array}$ & $\begin{array}{l}\text { 1.5T 2.0-mm thick; SPM5; GM } \\
\text { and WM volume }\end{array}$ & $\begin{array}{l}\uparrow \mathrm{GM} \text { volume in supramarginal gyrus } \\
\text { bilaterally, right postcentral gyrus, right } \\
\text { medial frontal gyrus, and right posterior } \\
\text { aspect of cerebellum; } \downarrow \text { GM volume in } \\
\text { right parahippocampal gyrus; } \downarrow \text { WM } \\
\text { volume in right anterior cingulate, left } \\
\text { superior parietal lobule }\end{array}$ & $(48)$ \\
\hline $\begin{array}{l}\text { ICD-10, ADI-R and ADOS; } \\
65 \text { people with either } \\
\text { Asperger's syndrome or } \\
\text { autism (male } 57 \text { ); IQ }>70 ; \\
\text { mean age } 31 \text { y (SD 10) }\end{array}$ & $\begin{array}{l}33 \text { gender-matched controls; } \\
\text { mean age } 32(\mathrm{SD} 9)\end{array}$ & $\begin{array}{l}1.5 \mathrm{~T} 1.5-\mathrm{mm} \text { thick; SPM2; GM } \\
\text { and WM volume; total brain } \\
\text { volume as a covariate in } \\
\text { ANCOVA }\end{array}$ & $\begin{array}{l}\downarrow \text { GM volume in medial temporal, fusiform } \\
\text { and cerebellar regions; } \downarrow \text { WM volume in } \\
\text { brainstem and portions of cerebellum }\end{array}$ & $(49)$ \\
\hline $\begin{array}{l}\text { ADI-R, ADOS-G; } 15 \text { males } \\
\text { with ASD; mean age } 22.7 \\
\text { y (SD 6.4) }\end{array}$ & $\begin{array}{l}13 \text { gender-, age-, IQ- and } \\
\text { handedness-matched } \\
\text { controls; mean age } 19.2 \\
\text { (SD 5.0) }\end{array}$ & $\begin{array}{l}\text { 3T 1-mm thick; GM and WM } \\
\text { density }\end{array}$ & $\begin{array}{l}\uparrow \text { GM density in midbrain bilaterally, left } \\
\text { reticular formation, right medial frontal } \\
\text { gyrus, left medial oribital frontal gyrus, and } \\
\text { middle frontal gyrus bilaterally; } \downarrow \text { GM } \\
\text { density in postcentral gyrus bilaterally; } \downarrow \\
\text { WM density in left anterior cerebellum and } \\
\text { in midbrain bilaterally }\end{array}$ & (19) \\
\hline
\end{tabular}

DSM, Diagnostic and Statistical Manual; ADI-R, Autism Diagnostic Interview-Revised; ADOS-G, Autism Diagnostic Observation Schedule-Generic; ANCOVA, analysis of covariance; ASP, Asperger's syndrome; BAMM, brain analysis morphological mapping; HFA, high-functioning autism. $\uparrow$, increased; $\downarrow$, decreased. All ages are listed in years. 
Table 2. Cortical-thickness-based studies for ASD

\begin{tabular}{|c|c|c|c|c|}
\hline ASD & Comparison & Methods & Findings (ASD relative to controls) & Reference \\
\hline $\begin{array}{l}\text { ADI-R, ADOS; autism (8 subjects), } \\
\text { Asperger's disorder (4 subjects), } \\
\text { or pervasive developmental } \\
\text { disorder not otherwise specified } \\
\text { (2 subjects); mean age } 33 \text { y } \\
\text { (SD 12) }\end{array}$ & $\begin{array}{l}14 \text { controls matched for sex, } \\
\text { age, intelligence quotient, } \\
\text { and handedness }\end{array}$ & $\begin{array}{l}\text { 1.5T, } 1.25 \mathrm{~mm} \text { thick T1; } \\
\text { FreeSurfer; voxelwise } t \text { test }\end{array}$ & $\begin{array}{l}\downarrow \text { Thickness in inferior frontal } \\
\text { gyrus pars opercularis, inferior } \\
\text { parietal lobule, and superior } \\
\text { temporal sulcus, precentral gyrus, } \\
\text { postcentral gyrus, inferior } \\
\text { occipital gyrus, prefrontal cortex, } \\
\text { anterior cingulate, medial parietal } \\
\text { cortex, supramarginal gyrus, and } \\
\text { middle and inferior temporal } \\
\text { cortex }\end{array}$ & (16) \\
\hline $\begin{array}{l}\text { ADI-R, ADOS; } 17 \text { male with } \\
\text { autism; mean age } 10.5 \mathrm{y} \\
\text { (SD 1.5) }\end{array}$ & $\begin{array}{l}14 \text { healthy male controls; } \\
\text { mean age } 10.7 \text { (SD 1.4) }\end{array}$ & $\begin{array}{l}1.5 \mathrm{~T}, 1.5 \mathrm{~mm} \text { thick } \mathrm{T} 1 \text {; Analysis of } \\
\text { Images, Networks and Systems } \\
\text { Software; } t \text { test }\end{array}$ & $\begin{array}{l}\uparrow \text { Thickness in the temporal and } \\
\text { parietal lobes but not in the } \\
\text { frontal and occipital lobes }\end{array}$ & (17) \\
\hline $\begin{array}{l}\text { DSM-IV, ADI-R and CARS; } 22 \\
\text { ASD (19 male); mean age } 9.2 \text { y } \\
\text { (SD 2.1) }\end{array}$ & $\begin{array}{l}16 \text { gender-, age-, handless-, } \\
\text { weight-, height-, } \\
\text { IQ-matched normal } \\
\text { controls }\end{array}$ & $\begin{array}{l}1.5 \mathrm{~T}, 2 \mathrm{~mm} \text { thick T1; FreeSurfer; } t \\
\text { test }\end{array}$ & $\begin{array}{l}\downarrow \text { Thickness in the right entorhinal, } \\
\text { right lateral orbitofrontal, left } \\
\text { lateral orbitofrontal, right medial } \\
\text { orbitofrontal, left medial } \\
\text { orbitofrontal cortex, right pars } \\
\text { triangularis; } \uparrow \text { thickness in the } \\
\text { left caudal anterior cingulate } \\
\text { cortex and left frontal pole }\end{array}$ & (18) \\
\hline $\begin{array}{l}\text { ADI-R, ADOS; } 15 \text { male with } \\
\text { autism; mean age } 22.7 \mathrm{y} \\
\text { (SD 6.4) }\end{array}$ & $\begin{array}{l}15 \text { typically developing } \\
\text { controls; mean age } 19.2 \\
\text { (SD 5.0) }\end{array}$ & $\begin{array}{l}\text { 3T, } 1.5 \mathrm{~mm} \text { thick T1; CIVET } \\
\text { software; general linear model } \\
\text { using age as a covariate }\end{array}$ & $\begin{array}{l}\uparrow \text { Thickness in the frontal } \\
\text { temporal, parietal, occipital, } \\
\text { cingulate gyrus, and fusiform } \\
\text { gyri; } \downarrow \text { thickness in the pre- and } \\
\text { postcentral gyri and paracentral } \\
\text { gyrus }\end{array}$ & (19) \\
\hline
\end{tabular}

DSM, Diagnostic and Statistical Manual; ADI-R, Autism Diagnostic Interview-Revised; ADOS, Autism Diagnostic Observation Schedule. All ages are listed in years. $\uparrow$, increased; $\downarrow$, decreased.

Hardan et al. (24) examined developmental changes in brain volume and cortical thickness in children with ASD, using structural MRI. Their study included 18 children with autism and 16 healthy age- and gender-matched controls. MRI scans were obtained at baseline and at follow-up. The mean time difference between the two scans was $2.1 \mathrm{y}$. The mean ages of ASD and control group were 10.9 y (SD 1.2) and 10.7 y (SD 1.2), respectively. They found differences in total GM volume over time, with significantly greater decreases in the autism group compared with controls. Differences in cortical thickness were also observed over time, with greater decreases in the autism group compared with controls in the frontal, temporal, and occipital lobes.

\section{Diffusion Tensor Imaging in ASD}

DTI (25) generates quantitative measures of WM tract integrity by providing detailed information about how water molecules diffuse within each voxel. Two widely used DTIderived features are fractional anisotropy (FA), which quantifies the spatial symmetry of diffusion, and the apparent diffusion coefficient (ADC), which quantifies the degree of restriction of diffusion. Other, less commonly examined, DTIderived features are mean diffusivity and radial diffusivity. Abnormalities in myelination, axonal number, diameter, and orientation can lead to changes in FA and ADC (26).

Most DTI studies of ASD have focused on ROI measurements, voxel-wise measurements, or fiber tracking (27-34). In a DTI study of the corpus callosum including 43 individuals with ASD [mean age, 16.2 y (SD 6.7)] and 34 age-matched controls, Alexander et al. found reduced FA, increased mean diffusivity, and increased radial diffusivity in the ASD group (29). These results suggested that the microstructure of the corpus callosum was affected in autism. Barnea-Goraly et al. (27) used DTI to investigate WM structural integrity in seven male children and adolescents with autism [mean age, $14.6 \mathrm{y}$ (SD 3.4)] and nine gender- and IQ-matched control subjects. Based on voxel-wise analysis, they found reduced FA values in brain regions that were implicated in theory-of-mind tasks (ventromedial prefrontal cortex, anterior cingulate, temporoparietal regions, and amygdala) and in social cognition (fusiform gyrus and adjacent to superior temporal sulcus). Additional clusters of reduced FA values were seen in occipitotemporal regions and in the corpus callosum. Sundaram et al. (33) used tractography to investigate frontal lobe DTI changes in 50 children with ASD [mean age, $4.75 \mathrm{y}$ (SD 2.43)] and 16 typically developing controls. There was a trend toward statistical significance in the FA of whole frontal lobe fibers $(p=0.1)$. They found that FA was significantly lower in the ASD group for short-range fibers $(p=0.003)$ but not for long-range fibers. There was no significant difference in the number of frontal-lobe fibers across groups.

Collectively, DTI-based ASD studies have consistently reported abnormalities of the corpus callosum across a broad age range (from young children to adults) (27-29,32,34). These studies have also consistently reported differences in 
prefrontal WM $(27,33,34)$, cingulate gyrus $(27,30,34)$, and internal capsule $(27,28,32,34)$.

\section{Diagnostic Models of ASD Based on MR-Derived Features}

MR-based diagnostic models hold the promise of complementing standard behavioral assessment of patients with ASD. Studies centering on MR-based diagnostic models usually involve three steps. First, investigators extract features from MR images; then they build a diagnostic model (a classifier) using machine-learning algorithms or statistical models; finally, investigators evaluate and validate the resulting diagnostic model.

Several studies centered on MR-based diagnostic models of ASD (18,35-37). For these studies, the mean age for the ASD group ranged from 6 to $33 \mathrm{y}$. Different features (volume, surface, and thickness) have been used to build diagnostic models of ASD. The sensitivity of these diagnostic models is in the range of $(0.77,0.95)$, the specificity is in $(0.75,0.92)$, and the accuracy is in $(0.81,0.87)$. Overall, MR-based diagnostic models can accurately differentiate individuals with ASD from normal controls.

The performance of a diagnostic model is critically affected by the feature types selected as components of that model. For example, Jiao et al. (18) compared thickness-based diagnostic models to those based on structure volumes. They used four machine-learning techniques to generate diagnostic models, and found thickness-based classification was superior to volume-based classification, for each combination of classifier and performance metric.

\section{Summary and Conclusion}

In reviewing recent advances in our understanding of structural MRI correlates of ASD, we have found several consistent patterns. Figure 1 illustrates these findings:

- ROI-based volumetry reveals that young children with ASD have abnormally increased total brain volume. In addition, juveniles and adults with ASD have reduced corpus callosum volume, and children with ASD have increased amygdala volume.

- VBM studies of ASD differ depending on whether a densitybased or volume-based analysis was performed. The majority of volume-based studies found increased GM volume in the frontal and temporal lobes, whereas most density-based studies found decreased GM density in these regions. For $\mathrm{WM}$, both volume and density tend to decrease in the temporal lobe.

- The majority of SBM studies of ASD reported increased cortical thickness in the parietal lobes.

- Longitudinal MRI studies of ASD reported abnormal growth trajectories in the frontal and temporal lobes.

- DTI studies of ASD consistently reported corpus-callosum abnormality across a wide age range. Differences in prefrontal WM, cingulate gyrus, and internal capsule were also consistently reported.
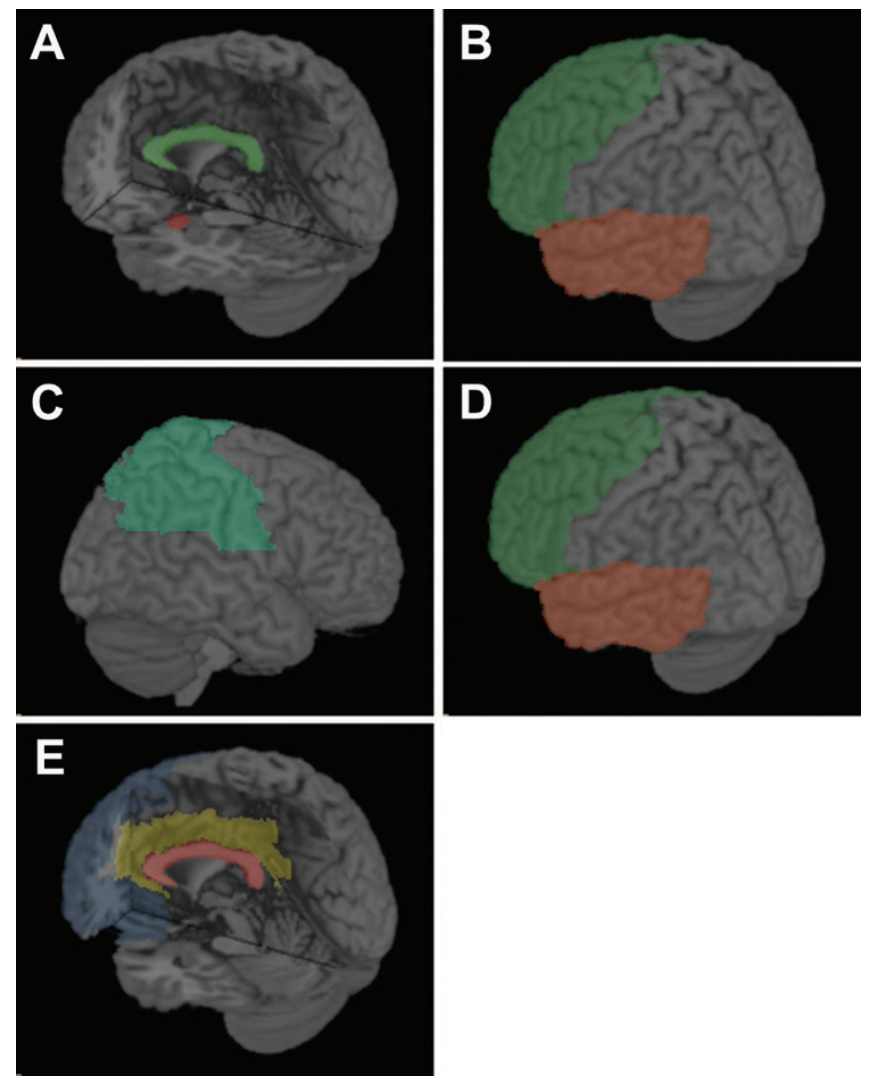

Figure 1. Findings of structural MRI studies in ASD. (A) ROI-based volumetry reveals that young children with ASD have increased total brain volume, juveniles and adults with ASD have reduced corpus-callosum (green) volume, and children with ASD have increased amygdala ( $r e d$ ) volume. $(B)$ VBM studies of ASD. The majority of volume-based studies found increased GM volume in the frontal (green) and temporal (orange) lobes; whereas most density-based studies found decreased GM density in these regions. (C) SBM studies of ASD reported increased cortical thickness in the parietal lobes (green). (D) Longitudinal MRI studies of ASD reported abnormal growth trajectories in the frontal (green) and temporal (orange) lobes. (E) DTI studies of ASD reported abnormalities in the corpus callosum (red), prefrontal WM (blue), cingulate gyrus (gold), and internal capsule (not shown).

- MR-based diagnostic models can differentiate individuals with ASD from controls with high sensitivity and specificity. However, the performance of diagnostic models was critically affected by the feature types that investigators selected.

Finally, we note that there were many conflicting findings regarding MR abnormalities in individuals with ASD. Many factors, such as inclusion and exclusion criteria, population age, MR acquisition parameters, details of the imageprocessing pipeline, feature extraction procedures, analytic methods used to detect group differences, and sample sizes, may have contributed to these disparities.

\section{REFERENCES}

1. Rapin I 1997 Autism. N Engl J Med 337:97-104

2. Geschwind DH, Levitt P 2007 Autism spectrum disorders: developmental disconnection syndromes. Curr Opin Neurobiol 17:103-111

3. Chakrabarti S, Fombonne E 2001 Pervasive developmental disorders in preschool children. JAMA 285:3093-3099

4. Eliez S, Reiss AL 2000 MRI neuroimaging of childhood psychiatric disorders: a selective review. J Child Psychol Psychiatry 41:679-694 
5. Courchesne E, Karns CM, Davis HR, Ziccardi R, Carper RA, Tigue ZD, Chisum HJ, Moses P, Pierce K, Lord C, Lincoln AJ, Pizzo S, Schreibman L, Haas RH, Akshoomoff NA, Courchesne RY 2001 Unusual brain growth patterns in early life in patients with autistic disorder: an MRI study. Neurology 57:245-254

6. Sparks BF, Friedman SD, Shaw DW, Aylward EH, Echelard D, Artru AA, Maravilla KR, Giedd JN, Munson J, Dawson G, Dager SR 2002 Brain structural abnormalities in young children with autism spectrum disorder. Neurology 59:184-192

7. Amaral DG, Schumann CM, Nordahl CW 2008 Neuroanatomy of autism. Trends Neurosci 31:137-145

8. Aylward EH, Minshew NJ, Field K, Sparks BF, Singh N 2002 Effects of age on brain volume and head circumference in autism. Neurology 59:175-183

9. Egaas B, Courchesne E, Saitoh O 1995 Reduced size of corpus callosum in autism. Arch Neurol 52:794-801

10. Hardan AY, Minshew NJ, Keshavan MS 2000 Corpus callosum size in autism Neurology 55:1033-1036

11. Manes F, Piven J, Vrancic D, Nanclares V, Plebst C, Starkstein SE 1999 An MRI study of the corpus callosum and cerebellum in mentally retarded autistic individuals. J Neuropsychiatry Clin Neurosci 11:470-474

12. Piven J, Bailey J, Ranson BJ, Arndt S 1997 An MRI study of the corpus callosum in autism. Am J Psychiatry 154:1051-1056

13. Schumann CM, Hamstra J, Goodlin-Jones BL, Lotspeich LJ, Kwon H, Buonocore MH, Lammers CR, Reiss AL, Amaral DG 2004 The amygdala is enlarged in children but not adolescents with autism; the hippocampus is enlarged at all ages J Neurosci 24:6392-6401

14. Stanfield AC, McIntosh AM, Spencer MD, Philip R, Gaur S, Lawrie SM 2008 Towards a neuroanatomy of autism: a systematic review and meta-analysis of structural magnetic resonance imaging studies. Eur Psychiatry 23:289-299

15. Mechelli A, Price CJ, Friston KJ, Ashburner J 2005 Voxel-based morphometry of the human brain: methods and applications. Curr Med Imaging Rev 1:105-113

16. Hadjikhani N, Joseph RM, Snyder J, Tager-Flusberg H 2006 Anatomical differences in the mirror neuron system and social cognition network in autism. Cereb Cortex 16:1276-1282

17. Hardan AY, Muddasani S, Vemulapalli M, Keshavan MS, Minshew NJ 2006 An MRI study of increased cortical thickness in autism. Am J Psychiatry 163:12901292

18. Jiao Y, Chen R, Ke X, Chu K, Lu Z, Herskovits EH 2010 Predictive models of autism spectrum disorder based on brain regional cortical thickness. Neuroimage 50:589-599

19. Hyde KL, Samson F, Evans AC, Mottron L 2010 Neuroanatomical differences in brain areas implicated in perceptual and other core features of autism revealed by cortical thickness analysis and voxel-based morphometry. Hum Brain Mapp 31:556-566

20. Hardan AY, Jou RJ, Keshavan MS, Varma R, Minshew NJ 2004 Increased frontal cortical folding in autism: a preliminary MRI study. Psychiatry Res 131:263-268

21. Brun CC, Nicolson R, Lepore N, Chou YY, Vidal CN, DeVito TJ, Drost DJ, Williamson PC, Rajakumar N, Toga AW, Thompson PM 2009 Mapping brain abnormalities in boys with autism. Hum Brain Mapp 30:3887-3900

22. Singer JD, Willett JB 2003 Applied Longitudinal Data Analysis: Modeling Change and Event Occurrence. Oxford University Press, New York

23. Schumann CM, Bloss CS, Barnes CC, Wideman GM, Carper RA, Akshoomoff N, Pierce K, Hagler D, Schork N, Lord C, Courchesne E 2010 Longitudinal magnetic resonance imaging study of cortical development through early childhood in autism. J Neurosci 30:4419-4427

24. Hardan AY, Libove RA, Keshavan MS, Melhem NM, Minshew NJ 2009 A preliminary longitudinal magnetic resonance imaging study of brain volume and cortical thickness in autism. Biol Psychiatry 66:320-326

25. Feldman HM, Yeatman JD, Lee ES, Barde LH, Gaman-Bean S 2010 Diffusion tensor imaging: a review for pediatric researchers and clinicians. J Dev Behav Pediatr 31:346-356

26. Beaulieu C 2002 The basis of anisotropic water diffusion in the nervous system - a technical review. NMR Biomed 15:435-455

27. Barnea-Goraly N, Kwon H, Menon V, Eliez S, Lotspeich L, Reiss AL 2004 White matter structure in autism: preliminary evidence from diffusion tensor imaging. Biol Psychiatry 55:323-326

28. Keller TA, Kana RK, Just MA 2007 A developmental study of the structural integrity of white matter in autism. Neuroreport 18:23-27

29. Alexander AL, Lee JE, Lazar M, Boudos R, DuBray MB, Oakes TR, Miller JN, Lu J, Jeong EK, McMahon WM, Bigler ED, Lainhart JE 2007 Diffusion tensor imaging of the corpus callosum in Autism. Neuroimage 34:61-73
30. Thakkar KN, Polli FE, Joseph RM, Tuch DS, Hadjikhani N, Barton JJ, Manoach DS 2008 Response monitoring, repetitive behaviour and anterior cingulate abnormalities in autism spectrum disorders (ASD). Brain 131:2464-2478

31. Conturo TE, Williams DL, Smith CD, Gultepe E, Akbudak E, Minshew NJ 2008 Neuronal fiber pathway abnormalities in autism: an initial MRI diffusion tensor tracking study of hippocampo-fusiform and amygdalo-fusiform pathways. J Int Neuropsychol Soc 14:933-946

32. Brito AR, Vasconcelos MM, Domingues RC, Hygino da Cruz LC Jr, Rodrigues Lde S, Gasparetto EL, Calcada CA 2009 Diffusion tensor imaging findings in schoolaged autistic children. J Neuroimaging 19:337-343

33. Sundaram SK, Kumar A, Makki MI, Behen ME, Chugani HT, Chugani DC 2008 Diffusion tensor imaging of frontal lobe in autism spectrum disorder. Cereb Cortex 18:2659-2665

34. Barnea-Goraly N, Lotspeich LJ, Reiss AL 2010 Similar white matter aberrations in children with autism and their unaffected siblings: a diffusion tensor imaging study using tract-based spatial statistics. Arch Gen Psychiatry 67:1052-1060

35. Akshoomoff N, Lord C, Lincoln AJ, Courchesne RY, Carper RA, Townsend J, Courchesne E 2004 Outcome classification of preschool children with autism spectrum disorders using MRI brain measures. J Am Acad Child Adolesc Psychiatry 43:349-357

36. Ecker C, Rocha-Rego V, Johnston P, Mourao-Miranda J, Marquand A, Daly EM, Brammer MJ, Murphy C, Murphy DG 2010 Investigating the predictive value of whole-brain structural MR scans in autism: a pattern classification approach Neuroimage 49:44-56

37. Ecker C, Marquand A, Mourao-Miranda J, Johnston P, Daly EM, Brammer MJ, Maltezos S, Murphy CM, Robertson D, Williams SC, Murphy DG 2010 Describing the brain in autism in five dimensions-magnetic resonance imaging-assisted diagnosis of autism spectrum disorder using a multiparameter classification approach. J Neurosci 30:10612-10623

38. Abell F, Krams M, Ashburner J, Passingham R, Friston K, Frackowiak R, Happe F, Frith C, Frith U 1999 The neuroanatomy of autism: a voxel-based whole brain analysis of structural scans. Neuroreport 10:1647-1651

39. McAlonan GM, Daly E, Kumari V, Critchley HD, van Amelsvoort T, Suckling J, Simmons A, Sigmundsson T, Greenwood K, Russell A, Schmitz N, Happe F, Howlin P, Murphy DG 2002 Brain anatomy and sensorimotor gating in Asperger's syndrome. Brain 125:1594-1606

40. Boddaert N, Chabane N, Gervais H, Good CD, Bourgeois M, Plumet M-H, Barthélémy C, Mouren M-C, Artiges E, Samson Y, Brunelle F, Frackowiak RS, Zilbovicius M 2004 Superior temporal sulcus anatomical abnormalities in childhood autism: a voxel-based morphometry MRI study. Neuroimage 23:364-369

41. Kwon H, Ow AW, Pedatella KE, Lotspeich LJ, Reiss AL 2004 Voxel-based morphometry elucidates structural neuroanatomy of high-functioning autism and Asperger syndrome. Dev Med Child Neurol 46:760-764

42. Waiter GD, Williams JH, Murray AD, Gilchrist A, Perrett DI, Whiten A 2004 A voxel-based investigation of brain structure in male adolescents with autistic spectrum disorder. Neuroimage 22:619-625

43. Waiter GD, Williams JH, Murray AD, Gilchrist A, Perrett DI, Whiten A 2005 Structural white matter deficits in high-functioning individuals with autistic spectrum disorder: a voxel-based investigation. Neuroimage 24:455-461

44. McAlonan GM, Cheung V, Cheung C, Suckling J, Lam GY, Tai KS, Yip L, Murphy DG, Chua SE 2005 Mapping the brain in autism. A voxel-based MRI study of volumetric differences and intercorrelations in autism. Brain 128:268-276

45. Rojas DC, Peterson E, Winterrowd E, Reite ML, Rogers SJ, Tregellas JR 2006 Regional gray matter volumetric changes in autism associated with social and repetitive behavior symptoms. BMC Psychiatry 6:56

46. McAlonan GM, Suckling J, Wong N, Cheung V, Lienenkaemper N, Cheung C, Chua SE 2008 Distinct patterns of grey matter abnormality in high-functioning autism and Asperger's syndrome. J Child Psychol Psychiatry 49:1287-1295

47. Bonilha L, Cendes F, Rorden C, Eckert M, Dalgalarrondo P, Li LM, Steiner CE 2008 Gray and white matter imbalance-typical structural abnormality underlying classic autism? Brain Dev 30:396-401

48. Ke X, Hong S, Tang T, Zou B, Li H, Hang Y, Zhou Z, Ruan Z, Lu Z, Tao G, Liu Y 2008 Voxel-based morphometry study on brain structure in children with highfunctioning autism. Neuroreport 19:921-925

49. Toal F, Daly EM, Page L, Deeley Q, Hallahan B, Bloemen O, Cutter WJ, Brammer MJ, Curran S, Robertson D, Murphy C, Murphy KC, Murphy DG 2010 Clinical and anatomical heterogeneity in autistic spectrum disorder: a structural MRI study. Psychol Med 40:1171-1181 